\title{
Optimasi dan Otomasi Pengaturan Kerja pada Sekolah
}

\author{
Astri Puji Lestari', Habibi Iberahim², Kiki Amelia Devi ${ }^{3}$, Muhammad Ainul Yaqin ${ }^{4}$ \\ 1,2,3 Teknik Informatika, Universitas Islam Negeri (UIN) Maulana Malik Ibrahim Malang \\ Jl. Gajayana No. 50 Malang 65144 - Indonesia \\ 16650070@student.uin-malang.ac.id ${ }^{1}, 16650021 @$ student.uin-malang.ac.id ${ }^{2}$, \\ 16650074@student.uin-malang.ac.id³ ${ }^{3}$ Yaqinov@ti.uin-malang.ac.id ${ }^{4}$
}

\begin{abstract}
Schools are formal educational institutions that are very important for the nation's children. Schools can successfully carry out the education process well, certainly not apart from the factors that support the success of the education process. In schools there are also several activities that will be carried out. It is necessary to arrange school working hours to carry out all these activities. This is in accordance with Ministerial Regulation No. 23 of 2017 concerning School Days, which regulates schools 8 hours a day for 5 days a week, and is officially implemented in the 2017-2018 school year. In addition to teaching, educators also become a committee in carrying out other activities at the School. It is necessary to assess criteria for each position including the amount of workload so that the burden of each person can be evenly and optimally. This problem can be solved by building a Decision Support System (SPK) application using the Profile Matching method. In this study, Profile Matching is used to recommend the best name for a position in the committee based on rank. Assessment is based on aspects of each position, which consists of core factors and secondary factors. Using this method can produce an optimal committee composition according to available resources and schedules.
\end{abstract}

Keywords: Work arrangement, Profile Matching, Core Factor, Secondary Factor

\begin{abstract}
Abstrak
Sekolah merupakan lembaga pendidikan formal yang sangat penting bagi anak bangsa. Sekolah dapat berhasil melaksanakan proses pendidikan dengan baik, tentunya tidak terlepas dari faktor-faktor yang mendukung keberhasilan proses pendidikan. Dalam sekolah juga terdapat beberapa kegiatan yang akan dilaksanakan. Perlu adanya pengaturan jam kerja sekolah untuk menjalankan semua kegiatan tersebut. Hal ini sesuai dengan Peraturan Menteri (Permen) Nomor 23 Tahun 2017 tentang Hari Sekolah, yang mengatur sekolah 8 jam sehari selama 5 hari dalam sepekan, dan resmi diterapkan pada tahun ajaran 2017-2018. Selain mengajar, para pendidik juga menjadi panitia dalam melaksanakan kegiatan lain di Sekolah. Perlu adanya peniliaian kriteria untuk setiap jabatan termasuk jumlah beban kerja agar beban tiap orang dapat merata dan optimal. Permasalahan ini dapat diselesaikan dengan membangun sebuah aplikasi Sistem Pendukung Keputusan (SPK) menggunakan metode Profile Matching. Pada penelitian ini, Profile Matching digunakan untuk memberikan rekomendasi nama terbaik untuk sebuah jabatan di kepanitiaan berdasarkan peringkat. Penilaian didasarkan atas aspek tiap jabatan, yang terdiri dari core factor dan secondary factor. Dengan menggunakan metode ini dapat menghasilkan susunan kepanitiaan yang optimal sesuai sumber daya dan jadwal yang ada dapat dilaksanakan.
\end{abstract}

Kata kunci: Pengaturan kerja, Profile Matching, Core Factor, Secondary Factor

\section{PENDAHULUAN}

Aktivitas belajar mengajar di sebuah sekolah haruslah sesuai dengan sumber daya yang ada, mulai dari guru hingga fasilitas pendukung lainnya. Selain kegiatan belajar mengajar, dalam sekolah juga terdapat kegiatan-kegiatan lainnya. Pada setiap kegiatan pasti dibutuhkan sumber daya manusia untuk dibentuk menjadi sebuah kepanitiaan. Tujuan dari kepanitiaan tersebut adalah agar dapat 
mengorganisir kegiatan tersebut dan dapat berjalan dengan lancar. Tiap kegiatan memiliki struktur kepanitiaan serta kriteria yang berbeda-beda. Selain itu beban kerja juga termasuk hal yang paling utama untuk dipertimbangkan. Hal ini agar beban kerja setiap karyawan atau pendidik sama rata sesuai dengan Peraturan Menteri (Permen) Nomor 23 Tahun 2017 tentang Hari Sekolah, yang mengatur sekolah 8 jam sehari selama 5 hari dalam sepekan, dan resmi diterapkan pada tahun ajaran 2017-2018. Permasalahan tersebut yang terkadanag menyulitkan untuk memilih orang yang sesuai dengan suatu jabatan di kepanitiaan.

Otomasi adalah suatu teknologi yang membuat sebuah proses dapat dikerjakan tanpa bantuan manusia otomasi (Automatic) diimplementasika denga menggunaka program perintah yang dikendalikan oleh sistem kontrol yang kemudian akan dieksekusi oleh sistem control [1]. Optimasi merupakan pencapaian suatu keadaan yang terbaik, yaitu pencapaian solusi masalah yang diarahkan pada batas maksimum dan minimum. Persoalan optimasi meliputi optimasi tanpa kendala dan optimasi dengan kendala. Dalam optimasi tanpa kendala, faktor- faktor yang menjadi kendala terhadap fungsi tujuan diabaikan sehingga dalam menentukan nilai maksimum ataupun minimum tidak ada batasan untuk berbagai pilihan peubah yang tersedia. Pada optimasi dengan kendala, faktofaktor yang menjadi kendala pada fungsi tujuan diperhatikan dan ikut dalam menentukan nilai maksimum ataupun minimum [2]. Profile matching adalah mekanisme pengambilan keputusan di mana setiap pelamar harus memiliki nilai yang ideal sesuai dengan variabel prediktor yang ditentukan, jadi pelamar bukan harus melampaui suatu tingkat varibel predictor [3].

Profile matching merupakan salah satu bagian dari Multicriteria decision making yang mengandung unsur objektif dan tujuan [4]. Sistem pendukung keputusan dengan metode profile matching dapat memberikan solusi untuk pengambilan keputusan yang objektif dan memiliki tujuan yang jelas [5]. Metode profile matching dapat digunakan untuk menyelesaikan masalah semi terstruktur seperti mencari kandidat untuk kepanitiaan tahun baru hijriah, di mana masalah tersebut sering dihadapi namun prosedur standar yang biasa digunakan belum mampu mengatasi permasalahan tersebut. Beban kerja serta kriteria-kriteria tertentu harus memenuhi syarat untuk sebuah jabatan di kepanitiaan. Penelitian ini menghasilkan solusi terhadap masalah yang ada dengan melakukan perhitungan yang sesuai dengan bobot kriteria untuk menentukan sebuah kepanitiaan untuk kegiatan tahun baru hijriah. Dengan menggunakan metode ini maka akan dihasilkan kandidat yang sesuai dengan posisi jabatan yang ada, serta akan membagi beban kerja yang sudah ada sebelumnya secara merata.

\section{METODOLOGI PENELITIAN}

\subsection{Analisis Sumber Daya dan Kebutuhan}

Dalam tahap ini dilakukan analisis sumber daya yang di butuhkan seperti jabatan kepanitian di acara Tahun Baru Hijriah serta meentukan kandidat. Setelah itu mendefinisikan kriteria yang di butuhkan untuk kepanitiaan tersebut. 


\subsection{Breakdown Aspek Penilaian}

Pada proses ini dilakukan pemecahan kriteria tiap jabatan menjadi lebih detail. Hal ini dimaksudkan agar proses penilaian tiap kandidat lebih mudah. Breakdown kriteria kandidat bedasarkan aspek yang dibutuhkan dalam suatu jabatan. Aspek ini yang akan menjadi acuan dalam pemberian penilaian dalam proses seleksi.

\subsection{Pemetean GAP Kompetensi}

GAP kompetensi adalah perbedaan antara kriteria yang dimiliki seseorang dengan kriteria yang diinginkan. Rumus GAP kompetensi yaitu: GAP = Profil kandidat - Profil jabatan. Contoh pemetaan gap kompetensi dapat dilihat pada Tabel 1.

Tabel 1. Pemetaan GAP

\begin{tabular}{|c|c|c|c|c|c|}
\hline No & Nama & 1 & 2 & 3 & \\
\hline 1 & Habibi & 4 & 3 & 2 & \multirow{5}{*}{ Profil Kandidat } \\
\hline 2 & Ibrahim & 4 & 4 & 1 & \\
\hline 3 & Kiki & 3 & 3 & 3 & \\
\hline 4 & Astri & 2 & 1 & 4 & \\
\hline 5 & Amelia & 1 & 2 & 3 & \\
\hline No & Nama & 1 & 2 & 3 & \\
\hline 1 & Habibi & 1 & 0 & 0 & GAP \\
\hline 2 & Ibrahim & 1 & 1 & -1 & \\
\hline 3 & Kiki & 0 & 0 & 1 & \\
\hline 4 & Astri & -1 & -2 & 2 & \\
\hline 5 & Amelia & -2 & -1 & 1 & \\
\hline
\end{tabular}

Pada baris pertama terdapat 3 kriteria penilaian, kriteria penilaian 1 dan 2 merupakan core factor dan penilaian 3 merupakan secondary factor. Lalu pada baris profil jabatan terdapat nilai ideal dari masing-masing faktor penilaian. 2 baris terakhir dari tabel merupakan nilai GAP dari masing-masing kandidat.

\subsection{Pembobotan}

Tahap ini dilakukan setelah kita mendapat gap dari tiap kandidat, pada tahap ini ditentukan bobot dari selisih yang diperoleh sesuai dengan ketentuan yang ada di Tabel 2.

Tabel 2. Bobot Nilai GAP

Keterangan Bobot Nilai GAP
\begin{tabular}{|r|r|l|}
\hline Selisih & $\begin{array}{c}\text { Bobot } \\
\text { Nilai }\end{array}$ & \\
\hline 0 & 5 & Tidak ada selisih (kompetensi sesuai dgn yg dibutuhkan) \\
\hline 1 & 4,5 & Kompetensi individu kelebihan 1 tingkat \\
\hline-1 & 4 & Kompetensi individu kekurangan 1 tingkat \\
\hline 2 & 3,5 & Kompetensi individu kelebihan 2 tingkat \\
\hline-2 & 3 & Kompetensi individu kekurangan 2 tingkat \\
\hline 3 & 2.5 & Kompetensi individu kelebihan 3 tingkat \\
\hline-3 & 2 & Kompetensi individu kekurangan 3 tingkat \\
\hline 4 & 1,5 & Kompetensi individu kelebihan 4 tingkat \\
\hline-4 & 1 & Kompetensi individu kekurangan 4 tingkat \\
\hline
\end{tabular}

Setelah menentukan pembobotan, maka akan diperoleh hasil dari GAP. 


\subsection{Perhitungan dan pengelompokkan Core Factor dan Secondary Factor}

Core factor atau faktor utama dan secondary factor atau faktor pendukung memiliki bobot penilaian yang berbeda. Core factor yang menjadi faktor yang utama dalam profil jabatan yang diseleksi akan memiliki presentase nilai yang lebih besar dibandingkan dengan secondary factor. Pada contoh kasus di atas, kriteria 1 dan 2 core factor dan kriteria 3 termasuk secondary factor. Rumus untuk menghitung Core Factor adalah sebagai berikut:

$$
N C F=\frac{\sum N C}{\sum I C}
$$

Keterangan:

NCF : Nilai rata-rata core factor

NC : Jumlah total nilai core factor

IC : Jumlah kompetensi core factor

Sedangkan rumus untuk menghitung Secondary Factor adalah sebagai berikut:

$$
N S F=\frac{\sum N S}{\sum I S}
$$

Keterangan:

NSF : Nilai rata-rata secondary factor

NS : Jumlah total nilai secondary factor

IS : Jumlah kompetensi secondary factor

Dalam perhitungan yang dilakukan sebelumnya untuk nilai pembobotan, lalu akan dihitung nilai dari core factor dan secondary factor seperti yang ditunjukan pada Tabel 3.

\begin{tabular}{|c|c|c|c|c|c|c|}
\hline No & Nama & 1 & 2 & 3 & NCF & NSF \\
\hline 1 & Habibi & 4.5 & 5 & 5 & 4.75 & 5.00 \\
\hline 2 & Ibrahim & 4.5 & 4.5 & 4 & 4.50 & 4.00 \\
\hline 3 & Kiki & 5 & 5 & 4.5 & 5.00 & 4.50 \\
\hline 4 & Astri & 4 & 3 & 3.5 & 3.50 & 3.50 \\
\hline 5 & Amelia & 3.5 & 4 & 4.5 & 3.75 & 4.50 \\
\hline
\end{tabular}

Tabel 3. Nilai Core Factor dan Secondary Factor

\subsection{Nilai Akhir}

Perhitungan nilai total merupakan mekanisme perhitungan nilai akhir dari tiap kandidat, nilai total ini akan mengolah nilai yang sebelumnya didapatkan dari pemetaan kriteria ke dalam 2 faktor yang telah dibagi. Pada tahap ini akan dihitung total nilai sesuai dengan presentase yang ditentukan. Rumus untuk menghitung nilai total yaitu sebagai berikut:

$$
N a=(x) \% N C F+(x) \% N S F
$$


Keterangan:

NCF : Nilai rata-rata core factor

NSF : Nilai rata-rata secondary factor

$\mathrm{Na} \quad$ : Nilai total

$(\mathrm{x}) \% \quad$ : Nilai persen yang diinputkan

Dimisalkan pada contoh kasus yang ada, nilai persentase untuk core factor adalah $60 \%$ dan untuk secondary factor adalah $40 \%$.

\section{HASIL DAN PEMBAHASAN}

Pada penelitian ini, Profile Matching digunakan untuk memberikan rekomendasi nama untuk jabatan kepanitiaan untuk kegiatan Tahun Baru Hijriah. Pemberian peringkat bertujuan untuk mendapatkan kandidat yang sesuai. Kepanitiaan yang dibutuhkan dalam kegiatan Tahun Baru Hijriah yaitu:

Tabel 3. Tabel Kriteria Jabatan Kepanitiaan

\begin{tabular}{|c|c|}
\hline Jabatan & Kriteria \\
\hline Penanggung Jawab & $\begin{array}{ll}\text { - } & \text { Memiliki jam kerja kurang dari maksimal } \\
\text { - } & \text { Bertanggung jawab } \\
\text { - } & \text { Bijaksana } \\
\end{array}$ \\
\hline Ketua Pelaksana & $\begin{array}{ll}\text { - } & \text { Memiliki jam kerja kurang dari maksimal } \\
\text { - } & \text { Memiliki jiwa kepemimpinan } \\
\text { - } & \text { Dapat berperilaku adil } \\
\text { - } & \text { Bertanggung jawab } \\
\text { - } & \text { Bijaksana }\end{array}$ \\
\hline Sekretaris & $\begin{array}{ll}\text { - } & \text { Memiliki jam kerja kurang dari maksimal } \\
\text { - } & \text { Memiliki keahlian dalam tulis menulis } \\
\text { - } & \text { Bertanggung jawab }\end{array}$ \\
\hline Bendahara & $\begin{array}{ll}\text { - } & \text { Dapat melakukan pembukuan keuangan dengan baik } \\
\text { - } & \text { Dapat memanajemen keuangan dengan baik } \\
\text { - } & \text { Memiliki jam kerja kurang dari maksimal } \\
\text { - } & \text { Bertanggung jawab } \\
\text { - } & \text { Jujur } \\
\text { - } & \text { Teliti }\end{array}$ \\
\hline Seksi Acara & $\begin{array}{ll}\text { - } & \text { Dapat memanajemen waktu dengan baik } \\
\text { - } & \text { Memiliki jam kerja kurang dari maksimal } \\
\text { - } & \text { Mudah berkomunikasi } \\
\text { - } & \text { Bertanggung jawab } \\
\text { - } & \text { Percaya diri }\end{array}$ \\
\hline Seksi Dokumentasi & $\begin{array}{ll}\text { - } & \text { Dapat menggunakan kamera dengan baik } \\
\text { - } & \text { Memiliki jam kerja kurang dari maksimal } \\
\text { - } & \text { Bertanggung jawab } \\
\end{array}$ \\
\hline Seksi Akomodasi & $\begin{array}{ll}\text { - } & \text { Memiliki jam kerja kurang dari maksimal } \\
\text { - } & \text { Bertanggung jawab } \\
\text { - } & \text { Memiliki SIM } \\
\end{array}$ \\
\hline Seksi Konsumsi & $\begin{array}{ll}\text { - } & \text { Memiliki jam kerja kurang dari maksimal } \\
\text { - } & \text { Bertanggung jawab }\end{array}$ \\
\hline
\end{tabular}

Berikut adalah flowchart untuk menghitung Core Factor dan Secondary Factor. 

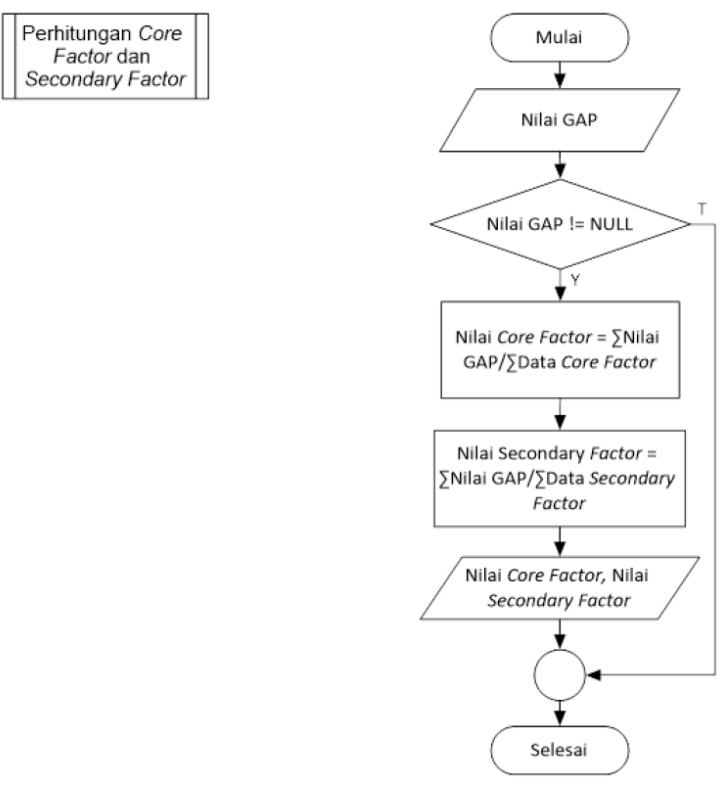

Gambar 1. Flowchart Perhitungan Core Factor dan Secondary Factor

Nilai akhir adalah proses akhir dari metode profile matching di mana proses alur perhitungan akhir dibuat berdasarkan Persamaan 3. Pada penelitian ini untuk menentukan nilai akhir, presentase untuk core factor adalah $70 \%$ dan presentase untuk secondary factor adalah 30\%. Flowchart perhitungan nilai akhir dapat dilihat pada Gambar 2.
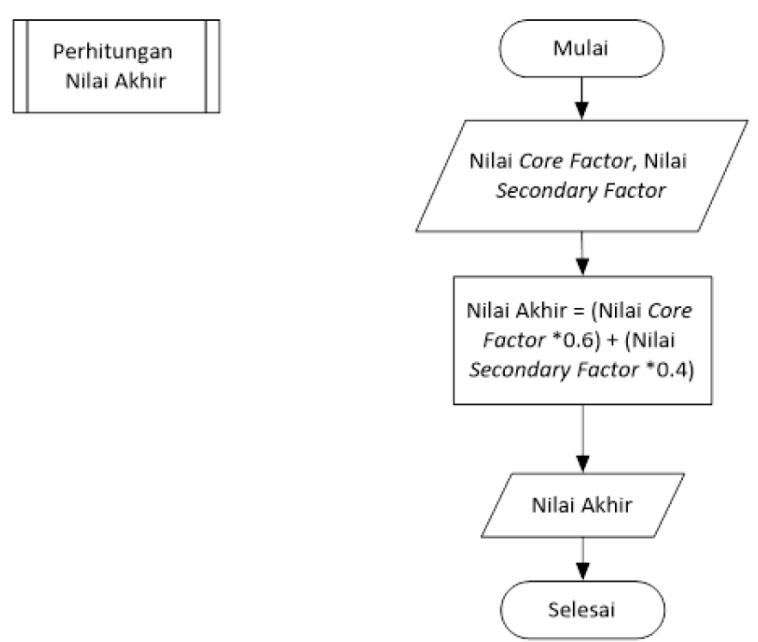

Gambar 2. Flowchart Perhitungan Nilai Akhir

Berikut adalah hasil perhitungan yang menghasilkan kandidat untuk semua jabatan untuk acara Tahun Baru Hijriah. 
Jurnal Riset Sistem Informasi Dan Teknik Informatika (JURASIK)

Volume 5 Nomor 1 Februari, pp 16-26

ISSN: 2527-5771/EISSN: 2549-7839

http://tunasbangsa.ac.id/ejurnal/index.php/jurasik

Tabel 5. Hasil akhir dan Pemilihan Kandidat Kepanitiaan Acara Tahun Baru Hijriah

\begin{tabular}{|l|c|c|c|c|c|c|c|c|}
\hline \multicolumn{7}{|c|}{ Daftar Kepanitian Kegiatan Tahun Baru Hijriah } \\
\cline { 2 - 12 } & Ari & Astri & Devi & Habibie & Ibrahim & Kiki & Puji & Tari \\
\hline Penanggung Jawab & 4.7 & 4.5 & 3.6 & 4.9 & 4.1 & 4.1 & 4.1 & 4.3 \\
\hline Ketua Pelaksana & 4.5 & 3.6 & 4.5 & 3.6 & 3.5 & 4.7 & 4.3 & 3.5 \\
\hline Sekretaris & 3.6 & 4.7 & 4.9 & 3.5 & 3.6 & 4.3 & 3.5 & 4.1 \\
\hline Bendahara & 4.3 & 4.3 & 4.7 & 4.5 & 4.3 & 3.6 & 4.8 & 4.1 \\
\hline Seksi Acara & 3.7 & 4.1 & 4.3 & 4.3 & 4.5 & 3.5 & 3.6 & 4.7 \\
\hline Seksi Dokumentasi & 4.1 & 3.7 & 3.5 & 4.7 & 4.9 & 4.5 & 4.1 & 3.6 \\
\hline Seksi Akomodasi & 4.9 & 3.5 & 3.7 & 4.1 & 4.7 & 3.7 & 4.5 & 3.7 \\
\hline Seksi Konsumsi & 3.5 & 5 & 4.1 & 3.7 & 3.7 & 4.7 & 3.7 & 4.5 \\
\hline \multicolumn{7}{|c|}{ Daftar Kepanitian Kegiatan Tahun Baru Hijriah } \\
\hline
\end{tabular}

Berikut adalah hasil perhitungan yang menghasilkan kandidat untuk semua jabatan untuk acara Masa Orientasi Siswa Baru.

Tabel 6. Hasil akhir dan Pemilihan Kandidat Kepanitiaan Acara Masa Orientasi Siswa Baru

\begin{tabular}{|l|c|c|c|c|c|c|c|c|c|c|c|c|}
\hline & \multicolumn{10}{|c|}{ Daftar Kepanitiaan Kegiatan Masa Orientasi Siswa baru } \\
\hline & Lestari & Hugo & Ira & Rizky & Lia & Abi & Aidan & Amel & Elio & Baskara & Ibra & Amelia \\
\hline Penanggung Jawa & 3,5 & 3,7 & 4,9 & 3,7 & 4,5 & 3,7 & 4,5 & 3,7 & 5 & 3,7 & 4,7 & 4,3 \\
\hline Ketua Pelaksana & 3,7 & 4,6 & 3,7 & 3,5 & 3,5 & 4,1 & 3,7 & 4,7 & 3,7 & 4,3 & 3,7 & 3,7 \\
\hline Sekretaris & 4,8 & 4,5 & 4,7 & 4,5 & 3,7 & 4,5 & 4,3 & 4,5 & 4,3 & 4,5 & 4,3 & 3,5 \\
\hline Bendahara & 4,5 & 3,5 & 4,5 & 3,7 & 3,7 & 4,3 & 3,5 & 4,1 & 4,5 & 4,7 & 4,6 & 4,5 \\
\hline Seksi Acara & 4,3 & 3,7 & 4,1 & 4,7 & 4,1 & 4,3 & 3,7 & 3,7 & 3,7 & 3,7 & 4,5 & 4,3 \\
\hline Seksi Upacara & 3,7 & 4,7 & 3,7 & 4,3 & 5 & 3,7 & 3,5 & 4,3 & 3,5 & 4,3 & 3,7 & 3,7 \\
\hline Seksi Lapangan & 4,7 & 3,7 & 4,9 & 4,1 & 4,1 & 3,5 & 3,7 & 4,5 & 3,7 & 3,7 & 5 & 3,7 \\
\hline Seksi Dokumentas & 4,7 & 4,8 & 3,7 & 4,1 & 4,3 & 3,5 & 4,3 & 4,5 & 4,7 & 3,5 & 4,5 & 4,5 \\
\hline Seksi Akomodasi & 3,7 & 3,5 & 3,5 & 4,1 & 4,7 & 5 & 4,3 & 4,5 & 3,7 & 3,6 & 3,5 & 4,5 \\
\hline Seksi Konsumsi & 3,5 & 3,6 & 5 & 3,7 & 3,7 & 4,3 & 4,7 & 3,5 & 4,3 & 4,1 & 4,7 & 4,7 \\
\hline Seksi Keamanan & 3,6 & 4,3 & 4,9 & 3,5 & 4,1 & 3,6 & 4,7 & 3,7 & 3,6 & 4,7 & 4,1 & 5 \\
\hline Seksi Kesehatan & 3,6 & 4,7 & 4,3 & 4,5 & 3,6 & 4,7 & 4,9 & 3,5 & 3,5 & 3,5 & 4,7 & 3,7 \\
\hline
\end{tabular}

Berikut adalah hasil perhitungan yang menghasilkan kandidat untuk semua jabatan untuk acara Hari Ulang Tahun Republik Indonesia. 
Jurnal Riset Sistem Informasi Dan Teknik Informatika (JURASIK)

Volume 5 Nomor 1 Februari, pp 16-26

ISSN: 2527-5771/EISSN: 2549-7839

http://tunasbangsa.ac.id/ejurnal/index.php/jurasik

Tabel 7. Hasil akhir dan Pemilihan Kandidat Kepanitiaan Acara Hari Ulang Tahun

Republik Indonesia

\begin{tabular}{|c|c|c|c|c|c|c|c|c|c|c|c|c|c|}
\hline \multicolumn{14}{|c|}{ Daftar Kepanitiaan Kegiatan Hari Kemerdekaan RI } \\
\hline & Kiran & Surya & Tyson & Ega & Eva & Vanda & Felix & E[i & Evander & Hendrix & Ivo & Elia & Hendri \\
\hline Penanggung Jawab & 3,5 & 4,7 & 3,7 & 4,5 & 5 & 3,6 & 3,7 & 4,9 & 4,5 & 4,1 & 3,7 & 4,1 & 4,5 \\
\hline Ketua Pelaksana & 3,6 & 3,7 & 3,5 & 4,3 & 4,7 & 4,7 & 4,3 & 3,7 & 3,5 & 5 & 4,3 & 3,7 & 4,1 \\
\hline Sekretaris & 3,7 & 4,5 & 4,3 & 3,6 & 3,7 & 4,5 & 4,7 & 4,7 & 3,7 & 4,9 & 5 & 3,5 & 3,7 \\
\hline Bendahara & 3,6 & 4,6 & 4,8 & 3,7 & 4,1 & 3,5 & 4,1 & 3,5 & 3,5 & 3,5 & 4,3 & 4,1 & 3,6 \\
\hline Seksi Acara & 3,7 & 4,3 & 4,8 & 4,5 & 4,5 & 4,7 & 4,7 & 4,3 & 5 & 4,3 & 3,7 & 3,7 & 4,5 \\
\hline Seksi Upacara & 4,7 & 3,5 & 3,6 & 4,3 & 3,5 & 4,5 & 4,5 & 4,3 & 4,3 & 4,5 & 4,3 & 4,3 & 4,1 \\
\hline Seksi Dekorasi & 4,5 & 3,6 & 3,5 & 4,6 & 4,5 & 4,7 & 4,3 & 4,5 & 4,3 & 4,1 & 4,1 & 3,5 & 3,7 \\
\hline Seksi Dokumentasi & 4,1 & 4,5 & 3,5 & 4,9 & 4,3 & 4,7 & 3,7 & 3,5 & 3,7 & 3,7 & 3,7 & 4,1 & 4,3 \\
\hline Seksi Akomodasi & 4,1 & 3,7 & 3,7 & 4,5 & 4,1 & 3,7 & 3,7 & 4,6 & 4,1 & 3,7 & 3,7 & 4,5 & 4,1 \\
\hline Seksi Lomba & 4,5 & 5 & 4,5 & 3,6 & 4,5 & 4,5 & 4,5 & 3,6 & 4,5 & 4,5 & 4,5 & 3,6 & 4,5 \\
\hline Seksi Konsumsi & 3,6 & 4,1 & 3,6 & 4,1 & 3,6 & 4,1 & 3,6 & 4,1 & 3,6 & 4,1 & 3,6 & 5 & 3,6 \\
\hline Seksi Keamanan & 4,5 & 3,6 & 4,5 & 4,5 & 4,5 & 3,6 & 5 & 4,5 & 4,5 & 3,6 & 4,5 & 4,5 & 4,5 \\
\hline Seksi Kesehatan & 3,7 & 4,5 & 4,1 & 3,7 & 3,7 & 4,5 & 4,1 & 3,7 & 3,7 & 4,5 & 4,1 & 3,7 & 5 \\
\hline
\end{tabular}

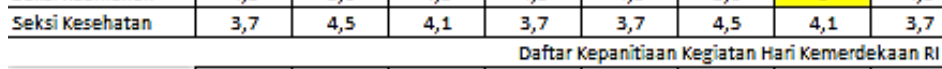

\begin{tabular}{|c|c|c|c|c|c|c|c|c|c|c|c|c|c|}
\hline & Kiran & Surya & Tyson & Ega & Eva & Vanda & Felox & Eli & Evander & Hendrix & Ivo & Amelia & Hendri \\
\hline Penanggung Jawab & & & & & $r$ & & & & & & & & \\
\hline Ketua Pelaksana & & & & & & & & & & $\sigma$ & & & \\
\hline Sekretaris & & & & & & & & & & & 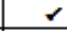 & & \\
\hline Bendahara & & & $\sigma$ & & & & & & & & & & \\
\hline Seksi Acara & & & & & & & & & $\checkmark$ & & & & \\
\hline Seksi Upacara & $\checkmark$ & & & & & & & & & & & & \\
\hline Seksi Dekorasi & & & & & & $\sigma$ & & & & & & & \\
\hline Seksi Dokumentasi & & & & $\checkmark$ & & & & & & & & & \\
\hline Seksi Akomodasi & & & & & & & & $\sigma$ & & & & & \\
\hline Seksi Lomba & & $\checkmark$ & & & & & & & & & & & \\
\hline Seksi Konsumsi & & & & & & & & & & & & $\checkmark$ & \\
\hline Seksi Keamanan & & & & & & & $\gamma$ & & & & & & \\
\hline Seksi Kesehatan & & & & & & & & & & & & & $\sigma$ \\
\hline
\end{tabular}

Berikut adalah hasil perhitungan yang menghasilkan kandidat untuk semua jabatan untuk acara Maulid Nabi Muhammad SAW.

Tabel 8. Hasil akhir dan Pemilihan Kandidat Kepanitiaan Acara Maulid Nabi Muhammad SAW

\begin{tabular}{|c|c|c|c|c|c|c|c|c|c|c|c|c|}
\hline \multicolumn{13}{|c|}{ Daftar Kepanitiaan Kegiatan Maulid Nabi Muhammad SAW } \\
\hline & Ali & Ita & Ana & Nala & Arvi & Ina & Inta & Arpina & Azhar & Anala & Brigid & Intan \\
\hline Penanggung Jawa & 3,5 & 3,7 & 4,8 & 4,5 & 4,3 & 3,7 & 4,7 & 4,7 & 3,7 & 3,5 & 3,6 & 3,6 \\
\hline Ketua Pelaksana & 3,7 & 4,6 & 4,5 & 3,5 & 3,7 & 4,7 & 3,7 & 4,8 & 3,5 & 3,6 & 4,3 & 4,7 \\
\hline Sekretaris & 4,9 & 3,7 & 4,7 & 4,5 & 4,1 & 3,7 & 4,9 & 3,7 & 3,5 & 5 & 4,9 & 4,3 \\
\hline Bendahara & 3,7 & 3,5 & 4,5 & 3,7 & 4,7 & 4,3 & 4,1 & 4,1 & 4,1 & 4,1 & 3,7 & 3,5 \\
\hline Seksi Acara & 4,5 & 4,5 & 3,5 & 3,7 & 4,1 & 5 & 4,1 & 4,3 & 4,7 & 3,7 & 4,1 & 3,6 \\
\hline Seksi Dekorasi & 3,7 & 4,1 & 4,5 & 4,3 & 4,3 & 3,7 & 3,5 & 3,5 & 5 & 4,3 & 3,6 & 4,7 \\
\hline Seksi Dokumentas & 4,5 & 3,7 & 4,3 & 3,5 & 3,7 & 3,5 & 3,7 & 4,3 & 4,3 & 4,7 & 4,7 & 4,9 \\
\hline Seksi Akomodasi & 3,7 & 4,7 & 4,5 & 4,5 & 3,7 & 4,3 & 4,5 & 4,5 & 4,5 & 3,5 & 3,7 & 3,5 \\
\hline Seksi Humas & 5 & 3,7 & 4,3 & 4,5 & 3,7 & 3,5 & 3,7 & 4,7 & 3,7 & 4,3 & 3,6 & 3,5 \\
\hline Seksi Konsumsi & 3,7 & 4,3 & 4,5 & 4,8 & 3,7 & 4,3 & 3,7 & 3,5 & 3,6 & 4,1 & 4,7 & 3,5 \\
\hline Seksi Keamanan & 4,7 & 3,7 & 4,3 & 4,6 & 4,5 & 3,7 & 5 & 4,5 & 3,5 & 4,7 & 4,1 & 4,7 \\
\hline Seksi Kebersihan & 4,3 & 3,7 & 3,5 & 4,5 & 4,3 & 3,7 & 3,7 & 4,5 & 4,5 & 4,7 & 5 & 3,7 \\
\hline \multicolumn{13}{|c|}{ Daftar Kepanitiaan Kegiatan Maulid Nabi Muhammad SAW } \\
\hline & Ali & Ita & Ana & Nala & Arvi & Ina & Inta & Arpina & Azhar & Anala & Brigid & Intan \\
\hline \multicolumn{2}{|l|}{ Penanggung Jawab } & & $\checkmark$ & & & & & & & & & \\
\hline Ketua Pelaksana & & & & & & & & $\checkmark$ & & & & \\
\hline Sekretaris & & & & & & & & & & $\checkmark$ & & \\
\hline Bendahara & & & & & $\checkmark$ & & & & & & & \\
\hline Seksi Acara & & & & & & $\checkmark$ & & & & & & \\
\hline Seksi Dekorasi & & & & & & & & & $\checkmark$ & & & \\
\hline \multicolumn{2}{|l|}{ Seksi Dokumentasi } & & & & & & & & & & & $\checkmark$ \\
\hline Seksi Akomodasi & & $\checkmark$ & & & & & & & & & & \\
\hline Seksi Humas & $\checkmark$ & & & & & & & & & & & \\
\hline Seksi Konsumsi & & & & $\checkmark$ & & & & & & & & \\
\hline Seksi Keamanan & & & & & & & $\checkmark$ & & & & & \\
\hline Seksi Kebersihan & & & & & & & & & & & $\checkmark$ & \\
\hline
\end{tabular}


Jurnal Riset Sistem Informasi Dan Teknik Informatika (JURASIK)

Volume 5 Nomor 1 Februari, pp 16-26

ISSN: 2527-5771/EISSN: 2549-7839

http://tunasbangsa.ac.id/ejurnal/index.php/jurasik

Berikut adalah hasil perhitungan yang menghasilkan kandidat untuk semua jabatan untuk acara Isro Mi'roj.

Tabel 9. Hasil akhir dan Pemilihan Kandidat Kepanitiaan Acara Isro Mi'roj

\begin{tabular}{|c|c|c|c|c|c|c|c|c|c|c|}
\hline \multicolumn{11}{|c|}{ Daftar Kepanitiaan Kegiatan Isro Mi'roj } \\
\hline & Eliane & Inggid & Cyra & Ane & Hayden & Savita & Helia & Hestia & Vita & Hestina \\
\hline Penanggung Jawab & 3,5 & 3,6 & 3,7 & 3,6 & 3,7 & 4,7 & 4,5 & 4,1 & 4,1 & 4,5 \\
\hline Ketua Pelaksana & 3,6 & 4,5 & 3,7 & 4,7 & 3,7 & 4,5 & 4,6 & 4,3 & 3,5 & 3,6 \\
\hline Sekretaris & 4,5 & 3,7 & 5 & 4,1 & 3,6 & 4,5 & 3,7 & 3,5 & 4,3 & 4,8 \\
\hline Bendahara & 4,8 & 3,6 & 3,5 & 3,5 & 3,7 & 4,5 & 3,6 & 4,5 & 4,1 & 4,5 \\
\hline Seksi Acara & 4,3 & 3,6 & 3,7 & 4,5 & 4,3 & 4,6 & 4,9 & 4,5 & 3,6 & 4,1 \\
\hline Seksi Dokumentasi & 4,5 & 3,7 & 5 & 4,7 & 3,7 & 4,1 & 4,5 & 3,5 & 4,5 & 4,3 \\
\hline Seksi Akomodasi & 4,1 & 5 & 3,6 & 4,5 & 3,7 & 3,6 & 4,7 & 4,5 & 3,5 & 4,7 \\
\hline Seksi Humas & 4,5 & 4,7 & 4,7 & 3,7 & 5 & 4,1 & 3,6 & 4,5 & 3,7 & 4,3 \\
\hline Seksi Konsumsi & 4,7 & 4,1 & 4,7 & 4,5 & 4,3 & 3,7 & 3,7 & 5 & 3,6 & 4,5 \\
\hline Seksi Kebersihan & 4,1 & 4,9 & 3,7 & 4,7 & 3,5 & 4,3 & 4,3 & 4,5 & 5 & 4,6 \\
\hline \multicolumn{11}{|c|}{ Daftar Kepanitiaan Kegiatan Isro Mi'roj } \\
\hline & Eliane & Inggid & Cyra & Ane & Hayden & Savita & Helia & Hestia & Vita & Hestina \\
\hline Penanggung Jawab & & & & & & $r$ & & & & \\
\hline Ketua Pelaksana & & & & $\checkmark$ & & & & & & \\
\hline Sekretaris & & & & & & & & & & 2 \\
\hline Bendahara & 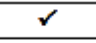 & & & & & & & & & \\
\hline Seksi Acara & & & & & & & $\checkmark$ & & & \\
\hline Seksi Dokumentasi & & & $\checkmark$ & & & & & & & \\
\hline Seksi Akomodasi & & $\checkmark$ & & & & & & & & \\
\hline Seksi Humas & & & & & $\checkmark$ & & & & & \\
\hline Seksi Konsumsi & & & & & & & & 2 & & \\
\hline Seksi Kebersihan & & & & & & & & & $\checkmark$ & \\
\hline
\end{tabular}

Berikut adalah hasil perhitungan yang menghasilkan kandidat untuk semua jabatan untuk acara Pondok Ramadhan.

Tabel 10. Hasil akhir dan Pemilihan Kandidat Kepanitiaan Acara Pondok Ramadhan

\begin{tabular}{|c|c|c|c|c|c|c|c|c|c|c|c|c|}
\hline & Hesti & Ida & Kamila & Linda & Esti & Idalia & Mila & Inda & Hestin & Alia & Kalinda & Mehri \\
\hline Penanggung Jawa & 3,6 & 4,1 & 4,5 & 3,7 & 4,5 & 3,5 & 3,7 & 3,5 & 5 & 4,3 & 4,3 & 3,7 \\
\hline Ketua Pelaksana & 4,1 & 4,5 & 3,6 & 4,5 & 3,7 & 4,1 & 5 & 4,9 & 3,5 & 4,3 & 4,5 & 4,1 \\
\hline Sekretaris & 3,7 & 3,7 & 4,5 & 4,1 & 3,6 & 4,5 & 3,7 & 4,3 & 3,5 & 4,3 & 5 & 4,3 \\
\hline Bendahara & 4,1 & 3,7 & 3,7 & 4,9 & 3,6 & 4,5 & 4,1 & 4,1 & 3,7 & 3,5 & 4,1 & 3,7 \\
\hline Seksi Acara & 4,3 & 3,5 & 4,1 & 4,5 & 3,6 & 5 & 4,5 & 3,7 & 4,5 & 4,1 & 3,7 & 3,6 \\
\hline Seksi Dekorasi & 4,5 & 4,1 & 3,7 & 4,3 & 4,1 & 4,5 & 3,6 & 4,5 & 3,6 & 4,7 & 4,5 & 5 \\
\hline Seksi Dokumentas & 4,3 & 3,7 & 4,1 & 4,9 & 3,5 & 4,5 & 3,6 & 5 & 4,3 & 4,1 & 3,7 & 3,5 \\
\hline Seksi Akomodasi & 5 & 3,6 & 4,5 & 4,9 & 4,7 & 4,3 & 3,5 & 3,7 & 4,1 & 4,9 & 3,6 & 3,5 \\
\hline Seksi Humas & 4,5 & 4,3 & 4,8 & 4,1 & 5 & 4,1 & 4,1 & 4,1 & 4,3 & 3,5 & 4,7 & 4,3 \\
\hline Seksi Konsumsi & 3,5 & 3,6 & 4,3 & 3,5 & 4,1 & 4,3 & 3,6 & 4,8 & 4,1 & 5 & 3,5 & 3,6 \\
\hline Seksi Keamanan & 4,7 & 4,9 & 4,5 & 4,1 & 3,6 & 4,7 & 3,7 & 4,5 & 3,7 & 3,7 & 4,7 & 3,7 \\
\hline Seksi Kebersihan & 4,5 & 4,9 & \begin{tabular}{|l|}
5 \\
\end{tabular} & 3,5 & 3,7 & 4,8 & 4,5 & 4,3 & 3,7 & 4,7 & 4,7 & 3,7 \\
\hline \multicolumn{13}{|c|}{ Daftar Kepanitiaan Kegiatan Pondok Ramadhan } \\
\hline & Hesti & Ida & Kamila & Linda & Esti & Idalia & Mila & Inda & Hestin & Alia & Kalinda & Mehri \\
\hline \multicolumn{2}{|c|}{ Penanggung Jawab } & & & & & & & & $\checkmark$ & & & \\
\hline Ketua Pelaksana & & & & & & & $\checkmark$ & & & & & \\
\hline Sekretaris & & & & & & & & & & & $\checkmark$ & \\
\hline Bendahara & & & & $\checkmark$ & & & & & & & & \\
\hline Seksi Acara & & & & & & $\checkmark$ & & & & & & \\
\hline \begin{tabular}{|l|l} 
Seksi Dekorasi & \\
\end{tabular} & & & & & & & & & & & & $\checkmark$ \\
\hline \multicolumn{2}{|l|}{ Seksi Dokumentasi } & & & & & & & $\checkmark$ & & & & \\
\hline Seksi Akomodasi & $\checkmark$ & & & & & & & & & & & \\
\hline Seksi Humas & & & & & $\checkmark$ & & & & & & & \\
\hline Seksi Konsumsi & & & & & & & & & & $\checkmark$ & & \\
\hline Seksi Keamanan & & $\checkmark$ & & & & & & & & & & \\
\hline Seksi Kebersihan & & & $\checkmark$ & & & & & & & & & \\
\hline
\end{tabular}


Jurnal Riset Sistem Informasi Dan Teknik Informatika (JURASIK)

Volume 5 Nomor 1 Februari, pp 16-26

ISSN: 2527-5771/EISSN: 2549-7839

http://tunasbangsa.ac.id/ejurnal/index.php/jurasik

Berikut adalah hasil perhitungan yang menghasilkan kandidat untuk semua jabatan untuk acara Hari Raya Idul Adha.

Tabel 11. Hasil akhir dan Pemilihan Kandidat Kepanitiaan Acara Hari Raya Idul Adha

\begin{tabular}{|c|c|c|c|c|c|c|c|c|c|c|c|c|}
\hline \multicolumn{11}{|c|}{ Daftar Kepanitiaan Kegiatan Hari Raya Idul Adha } & \multirow[b]{2}{*}{ Nuril } & \multirow{2}{*}{ Seraphina } \\
\hline & \begin{tabular}{|l|} 
Zainuri \\
\end{tabular} & Salama & Sera & Soli & Sunni & Nuri & Lana & Vina & Niva & Vesta & & \\
\hline Penanggung Jawa & 3,6 & 3,7 & 4,6 & 4,5 & 3,5 & 3,7 & 4,7 & 3,7 & 4,8 & 3,5 & 3,6 & 4,3 \\
\hline Koordinator & 4,7 & 4,9 & 3,7 & 4,7 & 4,5 & 4,1 & 3,7 & 4,9 & 3,7 & 3,5 & 5 & 4,9 \\
\hline Ketua Pelaksana & 4,3 & 3,7 & 3,5 & 4,5 & 3,7 & 4,7 & 4,3 & 4,1 & 4,1 & 4,1 & 4,1 & 3,7 \\
\hline Sekretaris & 3,5 & 4,5 & 4,5 & 3,5 & 3,7 & 4,1 & 5 & 4,1 & 4,3 & 4,7 & 3,7 & 4,1 \\
\hline Bendahara & 3,6 & 3,7 & 4,1 & 4,5 & 4,3 & 4,3 & 3,7 & 3,5 & 3,5 & 5 & 4,3 & 3,6 \\
\hline Seksi Lapangan & 4,7 & 4,5 & 4,8 & 4,3 & 3,5 & 3,7 & 3,5 & 3,7 & 4,3 & 4,3 & 4,7 & 4,7 \\
\hline Seksi Acara & 4,9 & 3,7 & 4,7 & 4,5 & 4,5 & 3,7 & 4,3 & 4,5 & 4,5 & 4,5 & 3,5 & 3,7 \\
\hline Seksi Dokumentas & 3,5 & 5 & 3,7 & 4,3 & 4,5 & 3,7 & 3,5 & 3,7 & 4,7 & 3,7 & 4,3 & 3,6 \\
\hline Seksi Akomodasi & 3,5 & 3,7 & 4,3 & 4,5 & 4,8 & 3,7 & 4,3 & 3,7 & 3,5 & 3,6 & 4,1 & 4,7 \\
\hline Seksi Humas & 3,5 & 4,7 & 3,7 & 4,3 & 4,6 & 4,5 & 3,7 & 5 & 4,5 & 3,5 & 4,7 & 4,1 \\
\hline Seksi Keamanan & 4,7 & 4,3 & 3,7 & 3,5 & 4,5 & 4,3 & 3,7 & 3,7 & 4,5 & 4,5 & 4,7 & 5 \\
\hline Seksi Kebersihan & 3,7 & 3,5 & 3,6 & 5 & 3,6 & 3,7 & 4,7 & 4,5 & 4,1 & 4,1 & 4,5 & 3,6 \\
\hline \multicolumn{13}{|c|}{ Daftar Kepanitiaan Kegiatan Hari Raya Idul Adha } \\
\hline & Zainuri & Salama & Sera & Soli & Sunni & Nuri & Lana & Vina & Niva & Vesta & Nuril & Seraphina \\
\hline \multicolumn{2}{|c|}{ Penanggung Jawab } & & & & & & & & $\checkmark$ & & & \\
\hline Koordinator & & & & & & & & & & & $\checkmark$ & \\
\hline Ketua Pelaksana & & & & & & $\checkmark$ & & & & & & \\
\hline Sekretaris & & & & & & & $\checkmark$ & & & & & \\
\hline Bendahara & & & & & & & & & & $\checkmark$ & & \\
\hline Seksi Lapangan & & & $\checkmark$ & & & & & & & & & \\
\hline Seksi Acara & $\checkmark$ & & & & & & & & & & & \\
\hline \multicolumn{2}{|l|}{ Seksi Dokumentasi } & $\checkmark$ & & & & & & & & & & \\
\hline Seksi Akomodasi & & & & & $\checkmark$ & & & & & & & \\
\hline Seksi Humas & & & & & & & & $\checkmark$ & & & & \\
\hline Seksi Keamanan & & & & & & & & & & & & $\checkmark$ \\
\hline Seksi Kebersihan & & & & $\checkmark$ & & & & & & & & \\
\hline
\end{tabular}

\section{SIMPULAN}

a. Metode profile matching berhasil diimplementasikan terhadap kasus pemilihan kepanitiaan untuk kegiatan tahun baru hijriah.

b. Dalam satu posisi atau jabatan memungkinkan untuk menambahkan isi kriteria baru, menghapus isi kriteria yang tidak dibutuhkan lagi, dan mengatur nilai GAP sesuai dengan kriteria yang diharapkan dalam pemilihan kandidat.

c. Ruang lingkup dalam penelitian ini hanya untuk beberapa kegiatan, sehingga dapat diperbanyak lagi.

\section{DAFTAR PUSTAKA}

[1] Arief, I. R. (2015). Perancangan Purwarupa Sistem Pengendalia kualitas Pengukuran Dimensi Produk Terotomasi. Jurnal Optimasi Sistem Industri ISSN 2088-4842/24428795.

[2] Kusrini. (2007). Konsep dan Aplikasi Sistem Pendukung Keputusan. Yogyakarta: Penerbit Andi.

[3] Soekartawi. (1992). Linear Programing Teori dan Aplikasinya Khususnya dalam Bidang Pertanian. Jakarta: Rajawali Pers.

[4] Wibowo, R. M. (2015). Penerapan Metode Profile Matching Untuk Aplikasi Multicriteria Decision Making (Studi Kasus :Pemilihan Guru Berprestasi). ISSN : 23023805 . 
[5] Suharyadi, S., Saifullah, S., Irawan, E., \& Sundari, R. (2019, September). Analisa Pemilihan Sales Terbaik di PT. Enseval Putera Megatreding Tbk, Pematangsiantar dengan metode Profil Matching. ISSN: 2686-0260

[6] Sinaga, B., \& Utami, Y. (2019). Sistem Pendukung Keputusan Penentuan Dosen Pembimbing Skripsi Menggunakan Metode Profile Matching (Studi Kasus: STMIK Pelita Nusantara Medan). Jurnal Mantik Penusa, 2(2). e-ISSN 2580-9741 p-ISSN 20883943

[7] Susilo, Andri Anto., (2017). Penerapan Metode Profile Matching pada Sistem Pendukung Keputusan Pemilihan Ketua Program Studi (Studi Kasus: Program Studi Teknik Informatika STMIK Musi Rawas). JUITA p-ISSN: 2086-9398; e-ISSN: 25798901; Volume V, Nomor 2

[8] Sudarmadi, A., Santoso E., \& Sutrisno, (2017). Sistem Pendukung Keputusan Pemilihan Personel Homeband Universitas Brawijaya Menggunakan Metode Profile Matching. Jurnal Pengembangan Teknologi Informasi dan Ilmu Komputer e-ISSN: 2548-964X Vol. 1, No. 12, Desember 2017, hlm. 1788-1796

[9] Angeline, M., \& Astuti, F., (2018). Sistem Pendukung Keputusan Pemilihan Karyawan Terbaik Menggunakan Metode Profile Matching. Jurnal Ilmiah Smart Volume II No.2, Desember $2018 \mathrm{Hal}$ : 45 - 51 pISSN : 2549-5836

[10] Nurfarida, E., \& Pradana, Andika K., (2018). Implementasi SPK Menggunakan Profile Matching Pencari Kerja Pada Dinas Tenaga Kerja Kabupaten Kediri. Jurnal \& Penelitian Teknik Informatika Volume 3 Nomor 1, Oktober 2018 e-ISSN : 2541-2019 p-ISSN : 2541-044X

[11] Amin, M., \& Cofriyanti, E., (2017). Sistem Rekomendasi Pemilihan Kandidat Calon Tenaga Kerja menggunakan Model Profile Matching. Prosiding SINTAK 2017 ISBN: 978-602-8557-20-7 